\title{
Indicators of sarcopenia and their relation to intrinsic and extrinsic factors relating to falls among active elderly women
}

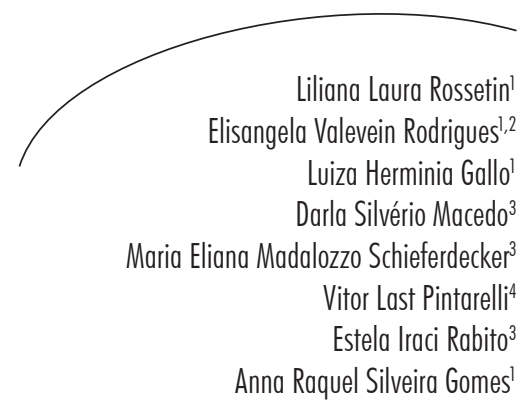

Abstract

Introduction: Musculoskeletal aging can impair functional performance increasing the risk of falls. Objective: To analyze the correlation between sarcopenia and the intrinsic and extrinsic factors involved in falls among community-dwelling elderly women. Method: A cross-sectional study evaluated the number of falls of 85 active community-dwelling elderly women in the previous year and then divided them into two groups: non-fallers $(n=61)$ and fallers $(n=24)$. The sarcopenia indicators assessed were gait speed $(G S, 10 m)$; handgrip strength (HS); calf circumference; appendicular muscle mass index (DXA). Intrinsic factors: Mental State Examination (MSE); visual acuity; depression (GDS-30); hip, knee (Lequesne) and ankle/foot (FAOS) pain/function; vestibular function (Fukuda test); functional mobility and risk of falls (TUG); power (sitting and standing five times); gait (treadmill); fear of falling (FES-I-Brazil). Extrinsic factors: risk/security features in homes. The independent $t$ test was applied for comparisons between groups and the Pearson and Spearman tests were used for correlations $(\mathrm{p}<0.05)$. Results: There was a moderate correlation between HS and GS in non-fallers $(\mathrm{r}=0.47 ; p=0.001)$ and fallers $(\mathrm{r}=0.54 ; p=0.03)$. There was a moderate negative correlation $(\mathrm{r}=-0.52 ; p=0.03)$ between FES-I-Brazil and gait cadence in fallers. There was a greater presence of stairs $(p=0.001)$ and throw rugs $(p=0.03)$ in the homes of fallers than non-fallers. Conclusion: The elderly women were not sarcopenic. Elderly fallers presented inferior gait cadence and a greater fear of falling. Residential risks were determining factors for falls, and were more relevant than intrinsic factors in the evaluation of falls among active community-dwelling elders.

\footnotetext{
Universidade Federal do Paraná, Setor de Ciências Biológicas, Departamento de Educação Física, Programa de Pós-graduação em Educação Física. Curitiba, Paraná, Brasil.

2 Instituto Federal do Paraná, Curso de Massoterapia. Curitiba, Paraná, Brasil.

3 Universidade Federal do Paraná, Setor de Ciências da Saúde, Departamento de Nutrição, Programa de Pós-graduação em Segurança Alimentar e Nutricional. Curitiba, Paraná, Brasil.

4 Universidade Federal do Paraná, Setor de Ciências da Saúde, Departamento de Clínica Médica, Curso de Medicina. Curitiba, Paraná, Brasil.

Key words: Sarcopenia; Accidental Falls; Gait; Muscle, Skeletal. 


\section{INTRODUCTION}

Falls are considered one of the most significant health problems for the elderly population. ${ }^{1}$ The etiology of falls is multi-factorial, including both intrinsic and extrinsic factors. ${ }^{2}$ Intrinsic factors include reduced strength and muscle power, modifications in gait, sight problems, functional, cognitive and balance issues, vestibular function, muscle reaction time, reductions in motion range, pain and psychological factors such as fear of falls and depression. ${ }^{3-7}$ Extrinsic factors include social conditions and environmental factors, such as: lighting; uneven surfaces; carpets and rugs; random objects on the ground; stairs without handrails and untethered animals. ${ }^{2}$ The risk of falls increases in accordance with age and the number of risk factors present. ${ }^{?}$

The reduction in muscle mass caused by the aging process should also be considered. Sarcopenia is a geriatric syndrome that involves diminished muscle mass and muscle function (strength or physical performance), which can affect the balance and gait of elderly persons. ${ }^{8}$

Several methods are available to assess muscle mass. The most common method in literature involves indirect estimates to assess the body composition using anthropometric data, such as the Body Mass Index (BMI), and bioimpedance. ${ }^{910}$ However, Dual Energy X-Ray Absorptiometry (DXA) is a more precise method and is the gold standard for assessments of body composition. This method can quantify fat content, muscle mass and body bone mass more accurately, especially among the elderly population..$^{9,11}$

The correlation between sarcopenia and balance in the elderly has previously been investigated. Studies have shown that muscle strength affects the static balance (feet together, tandem, semi-tandem, eyes open and eyes closed) and gait of elderly community-dwellers. Muscle mass in elderly men and women has been assessed using bioimpedance and plethysmography, with the only correlation found with balance in the tandem position., 810 Therefore, it is not yet known if muscle mass (assessed using DXA) and/or sarcopenia affect the factors involved in the risk of falls among the elderly.

We were unable to find any studies that investigated the main intrinsic and extrinsic factors related to falls in the elderly and their correlations with sarcopenia. ${ }^{12}$

Therefore, the aim of the present study was to assess indicators of sarcopenia and to correlate them with the intrinsic and extrinsic factors involved in the risk of falls among active, elderly, community dwellers who were classified as fallers or non-fallers.

\section{METHODS}

The present cross-sectional study received approval from the Research Ethics Committee of the Health Sciences Sector of the Universidade Federal do Paraná (Federal University of Paraná) under protocol number CAAE: 25239713.3.0000.0102.

The sample was calculated using $G^{*}$ Power 3.1 software, considering an effect size of 0.80 ; an $\alpha$ error of 0.05 and a power $(1-\beta)$ of $0.88 \%$. The total sample contained 83 elderly women.

The following inclusion criteria were applied: women; aged 65 years or more; healthy; functionally independent and capable of performing the required tests. The following exclusion criteria were applied: elderly women with neurological and/or trauma-orthopedic disorders; prostheses containing metallic or non-metallic implants that would hinder the performance of the proposed assessments; decompensated diseases and/or high blood pressure on the day of the assessment. In total, 85 elderly women participated in the present study, all of whom signed a free and informed consent form (FICF). 
The data was collected between August and December 2014. Firstly, the participants were assessed by a geriatric doctor who performed anamnesis and a physical examination, providing data related to previously diagnosed diseases, drug consumption, urinary and fecal incontinence, auditory acuity, current physical activity levels (and weekly routines) and psychosocial data: education (illiterate, 1-4 years, 5-8 years, >8 years); marital status; occupation; type of residence; and participation in social activities. The physical examination involved the collection of vital signs and a segmental examination, including a test of visual acuity using a Snellen card. Subsequently, physical assessments were performed to determine the body composition of the participants and the extrinsic and intrinsic factors related to falls.

Body mass was measured using scales (Filizola) and height was measured using a wall stadiometer (Sanny). BMI values were calculated using the body mass and height ratio squared, based on the classification of the Pan-American Health Organization. ${ }^{13}$

The participants were asked about the number of falls they had suffered in the previous 12 months and were classified as fallers if they had experienced one or more falls in that time period.

\section{Sarcopenia Indicators}

Sarcopenia screening used the values obtained in the tests for gait speed (GS), handgrip strength (HGS) and calf circumference (CC), as proposed by Cruz-Jentoft et al. ${ }^{14}$ In addition, appendicular muscle mass index (AMMI) was obtained using DXA.

GS was assessed on a rectilinear and flat 10-meter track. The first two meters and the last two meters were not included in the analysis to take into account phases of acceleration and deceleration. The time required to cover the remaining six meters was recorded in seconds (s). In the analysis, $>1 \mathrm{~m} / \mathrm{s}^{15}$ was considered to be an adequate speed, with no risk of falls.
HGS was measured by a manual dynamometer (SH), using the dominant limb of the participant. Three maximal movements were performed, with an interval of one minute of rest between each movement. The result (Kgf) was taken as the mean of the three attempts. ${ }^{14}$

CC was measured using a metric tape, which was placed around the widest point of the calf. Values of less than $31 \mathrm{~cm}$ were considered indicative of depleted muscle mass and correlated with incapacity. ${ }^{16}$

The AMMI and body composition assessments were performed using Dual Energy X-Ray Absorptiometry (DXA, Discovery A Hologic model). These assessments were conducted in the Laboratório Bioquímico e Densitométrico (Biochemistry and Densitometry Laboratory) (LABDEN) of the Universidade Tecnológica Federal do Paraná (Federal University of Technology of Paraná). The participants were positioned in dorsal decubitus, with their lower limbs rotated medially, their arms by their sides, their fingers together and the head aligned with the body. Absolute and percentage values were obtained for the body and its segments, using the following parameters: body fat; muscle mass; AMMI; upper leg muscle mass (ULMM); lower limb muscle mass (LLMM) and bone mineral content. ${ }^{9}$ The examination was carried out by a technician who had been trained by the International Society for Clinical Densitometry (ISCD). The equipment used was calibrated according to ISCD 2013-2015 regulations.

In order to calculate the AMMI, the sum of muscle mass and the bone mineral content of the four limbs was divided by the squared height of the individual. ${ }^{11}$

\section{Intrinsic factors related to falls}

A set of tests was conducted to investigate the main intrinsic factors related to falls. These tests are described below. 
Cognitive function was assessed using the Mini Mental State Examination (MMSE). The following scores were considered for the tests: 13 for illiterate individuals; 18 for individuals with one to seven years of education; and 26 for those with eight or more years of education. ${ }^{17}$ Depressive symptoms were assessed using the Geriatric Depression Scale (GDS-30), adopting a cutoff point of up to 10 points for the absence of depressive symptoms. ${ }^{18}$ Fear of falls was assessed using the Falls Efficacy Scale-International Brazil (FES-I-Brazil), in which the final score can range from 16 (not worried) to 64 (extremely worried). Scores of $\geq 23$ points were associated with a history of sporadic falls and those of $\geq 31$ points were associated with recurring falls. ${ }^{1}$ The individual health assessment involved answering the following question: "In general, do you consider your health to be: excellent; very good; good; poor; very poor". ${ }^{15}$

Hip and knee pain/function were assessed using the Lequesne algofunctional index, ${ }^{19}$ based on the following scores: 0 no impairment; $1-4$ little impairment; 5-7 moderate impairment; 8-10 severe impairment. The function and symptoms of the foot and ankle were assessed using the Foot and Ankle Outcome Score (FAOS), with a score of $>75$ points indicating a satisfactory function. ${ }^{20}$

The Human Activity Profile (HAP) was used to determine the level of physical activity, with the participants classified in one of the following categories: adjusted score activities (EAA) of $>74=$ active; between $53<$ EAA $<74=$ moderately active and $\mathrm{EAA}<53=$ inactive. ${ }^{21}$ The performance of activities of daily living (ADL) was assessed using the Katz Scale, ${ }^{22}$ considering 6 points as independent, 4 points as moderately dependent and 2 or less points as very dependent. Instrumental activities of daily living (IADL) were assessed using the Lawton scale, on which scores can range from 7 to 21, with higher scores representing better performance. ${ }^{23}$

Tactile sensitivity was assessed in the region of the first metacarpal and metatarsal of the dominant limb. To do so, an esthesiometer (Semmes-
Weinstein ${ }^{\circledR}$ ) applied slow pressure until reaching the force required to bend the filament, as per the manufacturer's instructions. The test began with a thinner filament $(0.05 \mathrm{~g})$. The participant was instructed to close their eyes and say "yes" when they felt pressure on the skin, as well as indicating where they felt the filament pressure. ${ }^{24}$

In order to assess the strength and muscle power of the lower limbs, the participant was asked to stand and sit in a chair five times, as quickly as possible, with their arms crossed in front of their body. The time (s) that elapsed between the instructor saying "now" and the end of the fifth movement was recorded. The following cutoff points were used: 60 to 69 years; 11.4 s; 70 to 79 years; $12.6 \mathrm{~s} ; 80$ to $89,12.7 \mathrm{s.}^{25}$

Functional mobility and the risk of falls were assessed using the timed up and go (TUG) test, which involves getting up from a chair without using the arms and walking at a comfortable and safe pace for three meters, before turning around, returning to the chair and sitting down again. ${ }^{26} \mathrm{At}$ the beginning and end of the test, the participant's back must touch the back of the chair. The time (s) was recorded and the following scores were considered: 60-69 years, $8.1 \mathrm{~s}$; 70-79 years, $9.2 \mathrm{~s}$; $80-99$ years, $11.3 \mathrm{s.}^{26}$

The Fukuda stepping test was performed to analyze vestibular dysfunction. ${ }^{27}$ The participant was asked to stand, with their eyes closed, and walk for 50 paces in an area with ground markings. Displacement of more than $0.5 \mathrm{~m}$ (measured with a metric tape) and/or a lateral rotation angle of more than 30 degrees (measured with a CARCI ${ }^{\circledR}$ goniometer) were indicative of an imbalance in the vestibular system. ${ }^{27}$

A treadmill (Gait Trainer 2- BIODEX) was used to assess gait speed $(\mathrm{m} / \mathrm{s})$, step length (m) and cadence (steps/minute). The participants were instructed to walk on the treadmill for three minutes, with the speed calculated based on the result of the GS test $(10 \mathrm{~m})$, which was completed in advance. Two attempts were made, with an interval of two minutes between each attempt: the 
first attempt was used to familiarize themselves with the procedure; the values recorded during the second attempt were used in the analysis. ${ }^{28}$

In the individual health assessment, each alternative received a decreasing numeric value (excellent 4 , very good 3 , good 2 , poor 1 and very poor 0 ) and was assessed in terms of absolute and relative frequency. The following factors were considered in the analysis: education (illiterate: 0; $1-4$ years: 1 ; $5-8$ years: 2 ; $>8$ years: 3 ); marital status (married 1 , separated 2 , divorced 4 , widow 5 , single 6); occupation (retired with other occupation 1 , retired without other occupation 2 ; domestic work 3, work outside the home 4); income [up to two minimum salaries (MS) 1, up to five MS 2, up to $10 \mathrm{MS} 3$, up to $20 \mathrm{MS} 4$ ]; type of residence (one-story house 1, two-story house 2, apartment 3); social activities (yes 1, no 0); auditory acuity (normal 1, hearing problem 2, uses a hearing aid 3); fecal and urinary incontinence (yes 1, no 0); sleep (normal 0, sleep disorder 1).

\section{Extrinsic factors related to falls}

The participants were also questioned about the risks and safety accessories in their homes, including: stairs; non-slip adhesives on stairs; handrails on stairs; ramps; non-slip adhesives on ramps; handrails on ramps; uneven surfaces (obstacle that need to be stepped over); loose carpets or rugs on the ground; anti-slip backing for carpets; loose pieces of wood on the ground; exposed cables or wires (extensions); slippery floors; poor lighting (causing vision problems); slippery-whenwet bathroom floor; handrails in bathrooms; high bed; high chair; high toilet; untethered animals; random objects on the ground. ${ }^{2}$

\section{Statistical analysis}

The normality of the data was assessed using the Shapiro-Wilk test and the results were expressed using descriptive statistics (mean, standard deviation, median, minimum and maximum), depending on the type of variable.

The independent $t$-test was used for comparisons between elderly fallers and non-fallers.

The following dependent variables were considered: cadence; gait speed; step length; handgrip strength; power (sit-to-stand test) and mobility (TUG). The following independent variables were used: demographic data; anthropometric data; clinical data; functional data; fear of falls; muscle mass and residential factors.

Pearson's correlation test or Spearman's correlation test were used to analyze the correlation between the parametric and nonparametric variables, respectively. In addition, when a moderate-high ( $r>0.30)$ and/or significant correlation $(p<0.05)$ was recorded, linear and multiple regression were used.

Statistical analysis was conducted using Excel $^{\circledR}$ and Statistica 12 (StastSoft) software, with the level of significance set at $p<0.05$.

\section{RESULTS}

Initially, 99 elderly individuals were contacted. However, five of these were not interested in participating in the research. Three were excluded due to uncontrolled hypertension, while another five gave up during the research and one began a program of health treatment. Thus, 85 elderly women, with a mean age of 70 years, participated in the present study. They were classified as overweight according to the BMI values $(28 \pm 4.53$ $\mathrm{kg} / \mathrm{m}^{2}$ ) and moderately-active according to the HAP score (62 \pm 9.67$)$. The participants were also stratified as fallers $(\mathrm{n}=24 ; 28.23 \%)$ and non-fallers ( $\mathrm{n}=61 ; 71.76 \%$ ), in accordance with their history of falls in the previous 12 months. The demographic, anthropometric, clinical and functional characteristics are displayed in Chart 1. 
Chart 1. Demographic, anthropometric, clinical and functional characteristics of elderly fallers and non-fallers. Curitiba-PR, 2015.

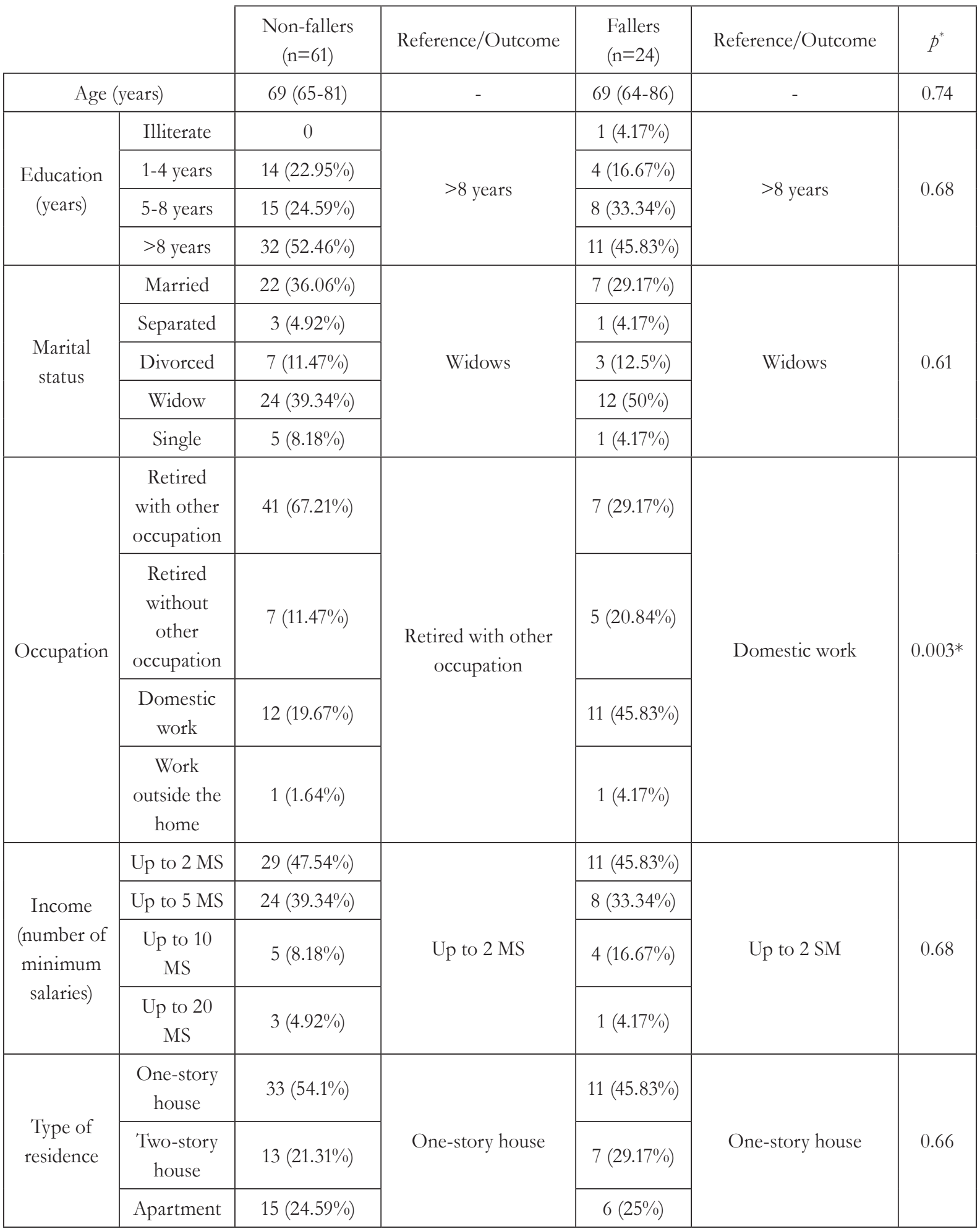


Continuation of Chart 1

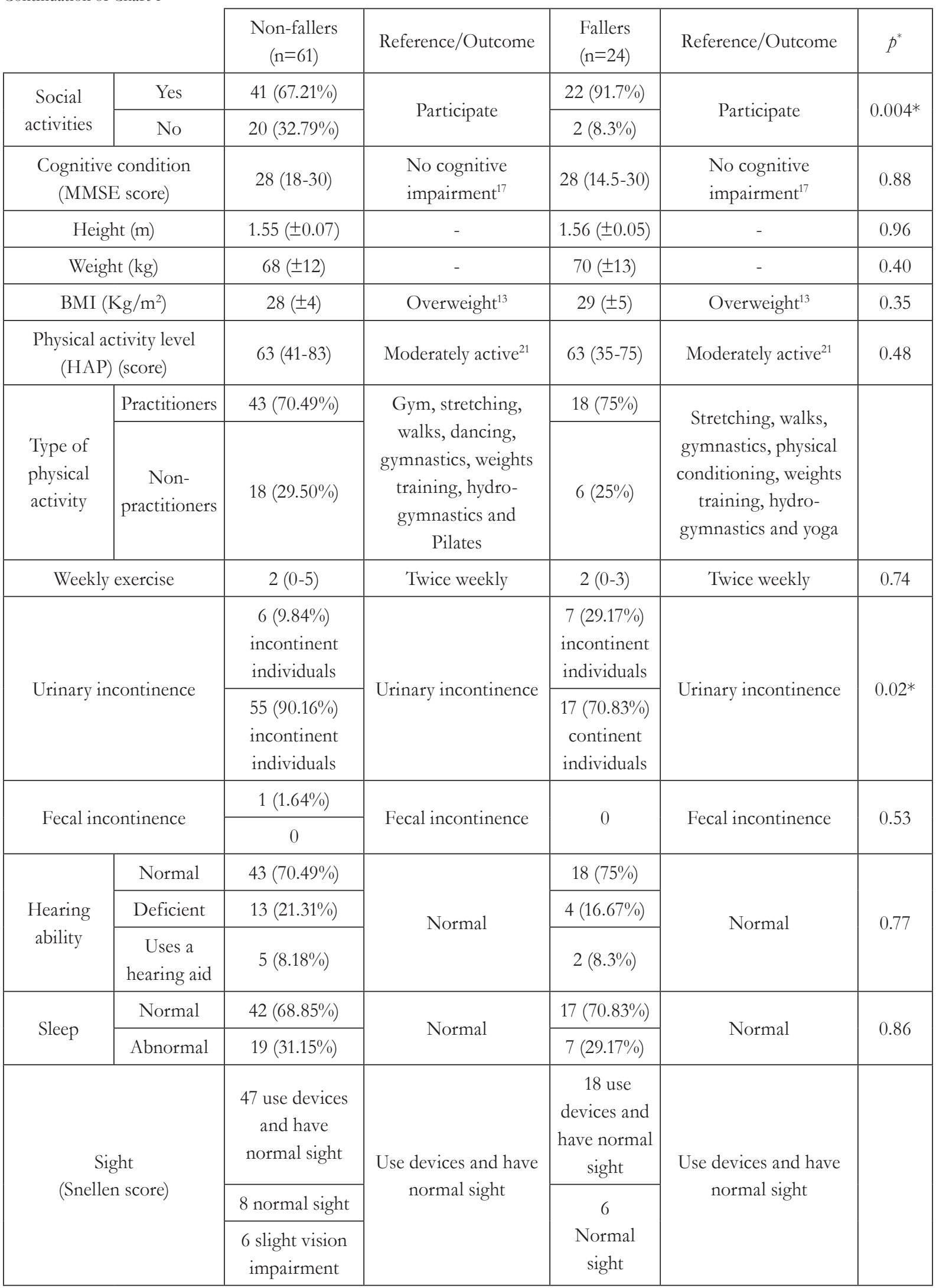


Continuation of Chart 1

\begin{tabular}{|c|c|c|c|c|c|c|}
\hline & & & & & \\
\hline & & $\begin{array}{l}\text { Non-fallers } \\
\quad(\mathrm{n}=61)\end{array}$ & Reference/Outcome & $\begin{array}{l}\text { Fallers } \\
(\mathrm{n}=24)\end{array}$ & Reference/Outcome & $p^{*}$ \\
\hline \multicolumn{2}{|c|}{$\begin{array}{c}\text { Vestibular function } \\
\text { (Fukuda test) angles in } \\
\text { degrees }\end{array}$} & $20( \pm 26)$ & $\begin{array}{l}\text { No indication of } \\
\text { an imbalance in the } \\
\text { labyrinthine system }{ }^{27}\end{array}$ & $25( \pm 24)$ & $\begin{array}{l}\text { No indication of } \\
\text { an imbalance in the } \\
\text { labyrinthine system }{ }^{27}\end{array}$ & 0.39 \\
\hline \multicolumn{2}{|c|}{$\begin{array}{l}\text { Sensitivity of the foot }(\mathrm{g}) \\
\text { (esthesiometer) }\end{array}$} & $0.2(0.05-4)$ & Normal & $0.2(0.05-10)$ & Normal & 0.25 \\
\hline \multicolumn{2}{|c|}{$\begin{array}{c}\text { ADL (Katz scale) } \\
\text { (score) }\end{array}$} & 6 & $\begin{array}{l}\text { Independent elderly } \\
\text { individuals }{ }^{22}\end{array}$ & 6 & $\begin{array}{l}\text { Independent elderly } \\
\text { individuals }{ }^{22}\end{array}$ & - \\
\hline \multicolumn{2}{|c|}{$\begin{array}{l}\text { IADL (Lawton scale) } \\
\text { score) }\end{array}$} & $20(17-21)$ & $\begin{array}{l}\text { Independent elderly } \\
\text { individuals } \\
\end{array}$ & $20(18-21)$ & $\begin{array}{l}\text { Independent elderly } \\
\text { individuals }{ }^{23}\end{array}$ & 0.84 \\
\hline \multicolumn{2}{|c|}{$\begin{array}{c}\text { Depression (Geriatric } \\
\text { Depression Scale- GDS- } \\
\text { 30) (score) }\end{array}$} & $6( \pm 4)$ & $\begin{array}{c}\text { No clinically } \\
\text { significant symptoms } \\
\text { of depression }^{18}\end{array}$ & $6( \pm 4)$ & $\begin{array}{c}\text { No clinically } \\
\text { significant symptoms } \\
\text { of depression }^{18}\end{array}$ & 0.73 \\
\hline \multicolumn{2}{|c|}{$\begin{array}{l}\text { Pain/hip function } \\
\text { (Lequesne) }\end{array}$} & $2( \pm 3)$ & Very little impairment & $2( \pm 2)$ & Very little impairment & 0.97 \\
\hline \multicolumn{2}{|c|}{$\begin{array}{l}\text { Pain/knee function } \\
\text { (Lequesne) (score) }\end{array}$} & $4( \pm 5)$ & Very little impairment & $4( \pm 3)$ & Very little impairment & 0.86 \\
\hline \multirow{5}{*}{$\begin{array}{c}\text { Pain/ankle } \\
\text { function } \\
\text { (FAOS) } \\
\text { (score) }\end{array}$} & Pain & $97(52.77-100)$ & \multirow{5}{*}{ No symptoms ${ }^{20}$} & $97(55-100)$ & \multirow{5}{*}{ No symptoms ${ }^{20}$} & 0.98 \\
\hline & $\begin{array}{c}\text { Other } \\
\text { symptoms }\end{array}$ & $96(35.71-100)$ & & $\begin{array}{c}93 \\
(57.14-100)\end{array}$ & & 0.44 \\
\hline & $\begin{array}{l}\text { Activities of } \\
\text { daily living }\end{array}$ & $100(60.71-100)$ & & $\begin{array}{c}100 \\
(82.35-100)\end{array}$ & & 0.35 \\
\hline & $\begin{array}{l}\text { Sport and } \\
\text { recreation }\end{array}$ & $100(15-100)$ & & $100(75-100)$ & & 0.51 \\
\hline & $\begin{array}{l}\text { Quality of } \\
\text { life }\end{array}$ & $100(43.75-100)$ & & $\begin{array}{c}87 \\
(43.75-100)\end{array}$ & & 0.38 \\
\hline \multirow{5}{*}{$\begin{array}{c}\text { General } \\
\text { health status }\end{array}$} & Excellent & $4(4.91 \%)$ & \multirow{5}{*}{ Good } & $4(0 \%)$ & & \multirow{5}{*}{0.09} \\
\hline & Very good & $3(11 \%)$ & & $3(8 \%)$ & & \\
\hline & Good & $2(77 \%)$ & & $2(79 \%)$ & Good & \\
\hline & Poor & $1(6 \%)$ & & $1(4 \%)$ & & \\
\hline & Very poor & $0(0 \%)$ & & $0(8 \%)$ & & \\
\hline
\end{tabular}

Reference values: Bertolucci et al. ${ }^{17}$; SABE ${ }^{13}$; Souza et al. ${ }^{21}$; Zhang \& Wang ${ }^{27}$; Lino et al. ${ }^{22}$; Lawton \& Brody ${ }^{23}$; Sousa et al. ${ }^{18}$; Imoto et al. ${ }^{20}$; *independent t-test; ADL: activities of daily living 
Among the demographic, anthropometric, clinical and functional characteristics, significant differences were found between elderly fallers and non-fallers for the variables occupation $(p=0.003)$, participation in social activities $(p=0.004)$ and urinary incontinence $(p=0.02)$.
No significant differences were found between the fallers and the non-fallers in relation to the intrinsic factors (muscle power; HGS; functional mobility; pain/joint function; vestibular function; sensory-motor skills; visual acuity; cognitive function; gait parameters; fear of falls and depression), as can be seen in Table 1 .

Table 1. Functional mobility, power, risk of falls, fear of falling and gait of elderly fallers and non-fallers. Curitiba-PR, 2015.

\begin{tabular}{|c|c|c|c|c|c|}
\hline & $\begin{array}{l}\text { Non-fallers } \\
\quad(\mathrm{n}=61)\end{array}$ & Outcome & $\begin{array}{l}\text { Fallers } \\
(\mathrm{n}=24)\end{array}$ & Outcome & $p^{*}$ \\
\hline $\begin{array}{l}\text { Functional } \\
\text { mobility/risk of } \\
\text { falls (s) } \\
\text { (TUG) }\end{array}$ & $7.64( \pm 1.25)$ & $\begin{array}{l}\text { Low risk of falls } \\
\text { and satisfactory } \\
\text { functional } \\
\text { mobility }^{25}\end{array}$ & $7.94( \pm 1.49)$ & $\begin{array}{l}\text { Low risk of falls } \\
\text { and satisfactory } \\
\text { functional } \\
\text { mobility }^{25}\end{array}$ & 0.40 \\
\hline $\begin{array}{l}\text { Muscle } \\
\text { strength/ } \\
\text { risk of falls (s) } \\
\text { (5XSST) }\end{array}$ & $11.02( \pm 1.80)$ & Low risk of falls ${ }^{26}$ & $11.05( \pm 2.25)$ & Low risk of falls ${ }^{26}$ & 0.95 \\
\hline \multirow{2}{*}{$\begin{array}{l}\text { Fear of falling } \\
\text { (score) } \\
\text { (FES-I-Brazil) }\end{array}$} & $25(16-45)$ & $\begin{array}{c}\text { History of } \\
\text { sporadic falls }\end{array}$ & $25(17-44)$ & $\begin{array}{c}\text { History of } \\
\text { sporadic falls }\end{array}$ & 0.73 \\
\hline & $(n=48)$ & & $(n=16)$ & & \\
\hline $\begin{array}{l}\text { Treadmill } \\
\text { speed }(\mathrm{m} / \mathrm{s})\end{array}$ & $\begin{array}{c}1.38 \\
(1.1-1.38)\end{array}$ & $\begin{array}{c}\text { Above the mean } \\
(0.70 \pm 1.92)^{29}\end{array}$ & $1.24( \pm 0.19)$ & $\begin{array}{c}\text { Above the mean } \\
(0.70 \pm 1.92)^{29}\end{array}$ & 0.67 \\
\hline $\begin{array}{l}\text { Cadence (steps/ } \\
\text { min) }\end{array}$ & $120( \pm 11.58)$ & $\begin{array}{c}\text { Normal } \\
(120.8 \pm 7.5)^{30}\end{array}$ & $121(111-156)$ & $\begin{array}{l}\text { Normal } \\
(119.4 \pm 9)^{30}\end{array}$ & 0.48 \\
\hline $\begin{array}{l}\text { Gait speed } \\
(\mathrm{cm} / \mathrm{s})\end{array}$ & $121( \pm 18)$ & $\begin{array}{c}\text { Below the mean } \\
128.3( \pm 15.6)^{30}\end{array}$ & $123( \pm 20)$ & $\begin{array}{c}\text { Below the mean } \\
125.8( \pm 15.9)^{30}\end{array}$ & 0.71 \\
\hline $\begin{array}{l}\text { Left step length } \\
\text { (cm) }\end{array}$ & $67.97( \pm 8.51)$ & $\begin{array}{l}\text { Normal }(63.7 \pm 5.8 \\
\mathrm{cm}^{30}\end{array}$ & $67.5( \pm 10.68)$ & $\begin{array}{c}\text { Normal }(63.2 \pm 6.5 \\
\mathrm{cm})^{30}\end{array}$ & 0.96 \\
\hline $\begin{array}{l}\text { Right step } \\
\text { length }(\mathrm{cm})\end{array}$ & $68.52( \pm 8.69)$ & $\begin{array}{c}\text { Normal }(63.7 \pm 5.8 \\
\mathrm{cm}^{30}\end{array}$ & $67.75( \pm 10.84)$ & $\begin{array}{c}\text { Normal }(63.2 \pm 6.5 \\
\mathrm{cm})^{30}\end{array}$ & 0.91 \\
\hline
\end{tabular}

Reference values: Bohannon ${ }^{25}$; Bohannon ${ }^{26}$; Camargos et al. ${ }^{1}$; Hallal et al. ${ }^{29}$; Moreira et al. ${ }^{30} ;{ }^{*}$ independent t-test; 5 XSST $=$ five times sit-to-stand test; TUG: timed up and go FES-I-Brazil: Falls Efficacy Scale-International. 
Sarcopenia screening

No sarcopenia indicators were found in either group (Chart 2), given that the values recorded in the GS, HGS and CC tests were all normal.
However, the muscle mass of the upper and lower limbs, as well as the AMMI of both groups, were below the reference values, although there were no significant differences between elderly fallers and non-fallers.

Chart 2. Sarcopenia screening among elderly fallers and non-fallers. Curitiba-PR, 2015.

\begin{tabular}{|c|c|c|c|c|c|c|c|}
\hline & $\begin{array}{l}\text { Non-fallers } \\
\quad(n=31) \\
60-69 \text { years }\end{array}$ & $\begin{array}{l}\text { Non-fallers } \\
\quad(\mathrm{n}=30) \\
70-80 \text { years }\end{array}$ & $\begin{array}{c}\text { Reference/ } \\
\text { Outcome }\end{array}$ & $\begin{array}{c}\text { Fallers } \\
(\mathrm{n}=14) \\
60-69 \text { years }\end{array}$ & $\begin{array}{c}\text { Fallers } \\
(\mathrm{n}=10) \\
70-80 \text { years }\end{array}$ & $\begin{array}{c}\text { Reference/ } \\
\text { Outcome }\end{array}$ & $p^{*}$ \\
\hline $\mathrm{GS}(\mathrm{m} / \mathrm{s})$ & $\begin{array}{c}1.48 \\
( \pm 0.26)\end{array}$ & - & $\begin{array}{c}\text { No risk of } \\
\text { falls }^{15}\end{array}$ & $\begin{array}{c}1.49 \\
( \pm 0.23)\end{array}$ & - & $\begin{array}{c}\text { No risk of } \\
\text { falls }^{15}\end{array}$ & 0.84 \\
\hline HGS $(\mathrm{Kg})$ & $22.21( \pm 55.84)$ & - & Adequate $^{14}$ & $\begin{array}{c}19.77 \\
( \pm 4.60)\end{array}$ & - & Adequate ${ }^{14}$ & 0.06 \\
\hline $\mathrm{CC}(\mathrm{cm})$ & $\begin{array}{c}35.2 \\
(27-53.5)\end{array}$ & - & Adequate $^{14}$ & $\begin{array}{l}35.99 \\
( \pm 4.14)\end{array}$ & - & Adequate $^{14}$ & 0.72 \\
\hline $\begin{array}{c}\text { AMMI-DXA } \\
\left(\mathrm{kg} / \mathrm{m}^{2}\right)\end{array}$ & $\begin{array}{c}6.49 \\
( \pm 0.68)\end{array}$ & $\begin{array}{c}6.02 \\
( \pm 0.74)\end{array}$ & $\begin{array}{l}\text { Below the } \\
\text { reference }^{11}\end{array}$ & $\begin{array}{c}6.66 \\
( \pm 0.55)\end{array}$ & $\begin{array}{c}6.10 \\
( \pm 0.89)\end{array}$ & $\begin{array}{l}\text { Below the } \\
\text { reference }^{11}\end{array}$ & $\begin{array}{r}0.38 / \\
0.80\end{array}$ \\
\hline $\begin{array}{l}\text { Muscle mass } \\
\text { ULMM (kg) }\end{array}$ & $\begin{array}{c}3.90 \\
( \pm 0.65)\end{array}$ & $\begin{array}{l}3.54 \\
( \pm 0.6)\end{array}$ & $\begin{array}{l}\text { Below the } \\
\text { reference }^{11}\end{array}$ & $\begin{array}{c}5.43 \\
( \pm 4.73)\end{array}$ & $\begin{array}{c}3.48 \\
( \pm 0.72)\end{array}$ & $\begin{array}{l}\text { Normal/ } \\
\text { Below the } \\
\text { reference }^{11}\end{array}$ & $\begin{array}{r}0.24 / \\
0.80\end{array}$ \\
\hline $\begin{array}{l}\text { Muscle mass } \\
\text { LLMM (kg) }\end{array}$ & $\begin{array}{c}11.03 \\
( \pm 1.86)\end{array}$ & $\begin{array}{l}10.48 \\
( \pm 1.74)\end{array}$ & $\begin{array}{l}\text { Below the } \\
\text { reference }^{11}\end{array}$ & $\begin{array}{c}10.24 \\
( \pm 1.94)\end{array}$ & $\begin{array}{c}11.59 \\
( \pm 1.29)\end{array}$ & $\begin{array}{l}\text { Below the } \\
\text { reference }^{11}\end{array}$ & $\begin{array}{r}0.24 / \\
0.74\end{array}$ \\
\hline
\end{tabular}

$\mathrm{GS}=$ gait speed; $\mathrm{HGS}=$ handgrip strength test $\mathrm{CC}=$ calf circumference; $\mathrm{AMMI}=$ appendicular muscle mass index; $\mathrm{ULMM}=$ upper limbs; LLMM $=$ lower limbs. Reference values: Studenski et al. ${ }^{15}$; Cruz-Jentoft et al. ${ }^{14}$; Coin et al. ${ }^{11} ; *$ independent t-test.

\section{Musculoskeletal correlations of elderly fallers and non-fallers}

Analysis of the muscle mass of the ULMM and HGS confirmed a slightly significant correlation $(\mathrm{r}=0.26 ; p=0.04)$ among the non-fallers. However, no significant correlation $(\mathrm{r}=0.17 ; p=0.23)$ was found for the fallers. Linear regression analysis indicated that only $0.6 \%$ of muscle mass could explain the HGS of elderly non-fallers $\left(\mathrm{r}^{2}=0.006\right.$ and $p=0.004)$.
A moderate and significant correlation was found between HGS and GS among elderly non-fallers $(\mathrm{r}=0.47 ; p=0.001)$ and fallers $(\mathrm{r}=$ $0.54 ; p=0.03)$, indicating that a stronger HGS is associated with a higher GS. The linear regression values between HGS and GS were $r^{2}=0.29$ and $p=0.005$ for fallers and $\mathrm{r}^{2}=0.22$ and $p=0.0001$ for non-fallers. These values demonstrate that $29 \%$ of HGS can affect the GS of fallers and $22 \%$ for non-fallers. 
A moderate, negative and significant correlation $(\mathrm{r}=-0.52 ; p=0.03)$ was found between the FES-IBrazil and the gait cadence of fallers, indicating that increases in gait cadence decrease fear of falls. The linear regression values were $r^{2}=0.25$ and $p=0,004$, indicating that $25 \%$ of gait cadence can affect fear of falls among elderly fallers.
In the multiple linear regression analysis of the HGS, FES-I-Brazil and GS values, it was found that $53 \%\left(\mathrm{r}^{2}=0.53 ; p=0.0003\right)$ and $31 \%\left(\mathrm{r}^{2}=0.31\right.$; $p=0.0001$ ) of the HGS and fear of falls (FES-IBrazil) explained the GS of elderly fallers and non-fallers, respectively.

Table 2 displays the results of the musculoskeletal correlations.

Table 2. Musculoskeletal correlations of elderly fallers and non-fallers. Curitiba-PR, 2015.

\begin{tabular}{|c|c|c|c|c|}
\hline & \multicolumn{2}{|c|}{$\begin{array}{c}\text { Non-fallers } \\
n=61\end{array}$} & \multicolumn{2}{|c|}{$\begin{array}{c}\text { Fallers } \\
\mathrm{n}=24\end{array}$} \\
\hline & $\mathrm{r}$ & $\mathrm{p}$ & $\mathrm{r}$ & $\mathrm{p}$ \\
\hline Muscle mass ULMM x HGS & 0.26 & $0.04 *$ & 0.15 & 0.45 \\
\hline Muscle mass LLMM x 5XSST & 0.03 & 0.77 & 0.01 & 0.94 \\
\hline HGS $x$ gait speed & 0.47 & $0.0001 *$ & 0.54 & $0.005^{*}$ \\
\hline \multirow[t]{3}{*}{ TUG x FES-I-Brazil } & 0.09 & $0.53^{\#}$ & 0.22 & $0.40^{\#}$ \\
\hline & \multicolumn{2}{|c|}{$\begin{array}{c}\text { Non-fallers } \\
\mathrm{n}=48\end{array}$} & \multicolumn{2}{|c|}{$\begin{array}{c}\text { Fallers } \\
n=16\end{array}$} \\
\hline & $\mathrm{r}$ & $p$ & $\mathrm{r}$ & $p$ \\
\hline Gait cadence x TUG & 0.15 & 0.29 & -0.11 & $0.67^{\#}$ \\
\hline Gait cadence x FES-I-Brazil & 0.17 & $0.23^{\#}$ & -0.52 & $0.03^{\#}$ \\
\hline Step length x TUG & 0.15 & 0.30 & 0.13 & 0.62 \\
\hline Step length x FES-I-Brazil & -0.13 & $0.36^{\#}$ & 0.14 & $0.58^{\#}$ \\
\hline
\end{tabular}

LLMM= lower limbs; TUG = timed up and go; 5XSST= five times sit-to-stand test; FES-I-Brazil= Falls Efficacy Scale International Brazil; \#Spearman correlation; the other variables were analyzed using Pearson's correlation; * $\mathrm{p}<0.05$ Pearson's correlation.

\section{Extrinsic/environmental factors related to the risk of falls}

Analysis of the extrinsic factors related to the risk of falls confirmed the following statistically significant differences between type of residence in both groups: the presence of stairs; the presence of rugs; and the presence of loose pieces of wood on the floor. Elderly fallers did not report the presence of exposed wires and extensions, whereas $6.55 \%$ of the fallers did so. The non-fallers reported high toilets in their homes, unlike the fallers. Table 3 displays these results. 
Table 3. Extrinsic factors related to the risk of falls in elderly individuals. Curitiba-PR, 2015.

\begin{tabular}{lcccc}
\hline $\begin{array}{c}\text { Risks and safety resources found in the } \\
\text { homes of the participants }\end{array}$ & $\%$ & $\begin{array}{c}\text { Non-fallers } \\
\mathrm{n}=61\end{array}$ & $\begin{array}{c}\text { Fallers } \\
\mathrm{n}=24\end{array}$ & $p^{*}$ \\
\hline Stairs & 54.11 & 54.45 & 58.33 & $0.001^{*}$ \\
Non-slip adhesive on stairs & 10.58 & 9.83 & 12.50 & 0.09 \\
Handrails on stairs & 35.29 & 34.42 & 37.50 & 0.86 \\
Ramps & 24.70 & 26.22 & 20.83 & 0.75 \\
Non-slip adhesive on ramps & 4.70 & 6.55 & 0 & 0.16 \\
Handrails on ramps & 2.35 & 1.63 & 4.16 & 0.06 \\
Any obstacles on the ground (that would & 34.11 & 31.14 & 41.66 & 0.65 \\
have to be stepped over) & & & & \\
Loose carpets & 64.70 & 63.93 & 66.66 & $0.03^{*}$ \\
Non-slip adhesive for carpets & 31.76 & 29.50 & 37.50 & 0.69 \\
Pieces of wood on the floor & 2.35 & 1.63 & 4.16 & $0.03^{*}$ \\
Exposed cables, wires (extensions) & 4.70 & 6.55 & 0 & $0.03^{*}$ \\
Slippery floor & 35.29 & 34.42 & 37.50 & 0.68 \\
Poor lighting (hindering sight) & 16.47 & 16.39 & 16.66 & 0.32 \\
Slippery-when-wet bathroom floor & 50.58 & 52.45 & 45.83 & 0.87 \\
Handrails in bathrooms & 21.17 & 22.95 & 16.66 & 0.33 \\
High bed & 35.29 & 36.06 & 33.33 & 0.65 \\
High chair & 10.58 & 9.83 & 12.50 & 0.06 \\
High toilet & 2.35 & 3.27 & 0 & $0.01^{*}$ \\
Pets (ex. cat, dog) & 36.47 & 42.62 & 20.83 & 0.35 \\
Random objects on the floor (ex. shoes, & 25.88 & 22.95 & 33.33 & 1 \\
boxes, toys, etc.) & & & & \\
\hline & & & & \\
\hline
\end{tabular}

${ }^{*} p<0.05$ independent t-test.

\section{DISCUSSION}

The sociodemographic characteristics of the elderly community-dwellers assessed in the present study were as follows: a mean age of 71 years; more than eight years of education; preserved cognitive state; retired with other occupation; a mean income of up to two minimum salaries; widows; adequate auditory and visual acuity; independent in relation to ADL and IADL.

According to the sarcopenia screening methods proposed by the European Sarcopenia Council, ${ }^{14}$ none of the participants (fallers and non-fallers) exhibited risk indicators. However, when assessed using a more precise method (DXA), the muscle mass values were below the recommended level for their age group, ${ }^{11,14}$ despite the fact that neither their musculoskeletal function nor their physical performance were affected..$^{14,15,26}$ This highlights the importance of conducting more accurate assessments in order to prevent sarcopenia.

Concerning falls, even the participants classified as moderately active (mean of two sessions of physical exercise per week) were associated with 
an occurrence rate of $28 \%$ for falls, which is similar to the results found in another Brazilian study. ${ }^{31}$ When the intrinsic factors related to falls (power, muscle force, functional mobility, pain, vestibular function, sensory motor skills, visual acuity, cognitive function, gait, fear of falls and depression) were analyzed, no statistically significant differences were found between elderly fallers and non-fallers. ${ }^{7,31}$

However, extrinsic factors such as the presence of stairs, rugs and pieces of loose wood were more common in the homes of fallers than in those of the non-fallers. Meta-analysis of the effects of environmental factors on the risk of falls among the elderly population concluded that residential interventions should be a part of planning strategies to prevent falls. In addition, when these residential interventions are completely understood by the elderly and adopted as safety measures, there is a significant reduction in the number of falls recorded. ${ }^{2}$

Concerning the characteristics of the participants, it was found that $76 \%$ of the elderly women had normal vision and $72 \%$ had normal hearing. This data is contrary to the results reported by other authors: $61 \%$ of elderly individuals had poor or regular vision and $31 \%$ had poor or regular hearing, with a $31 \%$ frequency of falls. ${ }^{31}$ These outcomes could indicate that although visual and auditory acuity are intrinsic factors related to the risk of falls, in the present study, the occurrence of falls was similar among the moderately-active community-dwelling elderly women with normal visual and auditory acuity and community-dwelling elderly women with deficits in these areas. ${ }^{31}$ Thus, it is possible to suggest that visual and auditory acuity are not determining factors for the risk of falls among active, community-dwelling, elderly women.

Despite the fact that most of the participants suffered from urinary incontinence, a significant difference was found between non-fallers (90\%) and fallers $(70 \%)$. Borges et al. ${ }^{32}$ conducted a profile study of 197 elderly individuals in convenience groups and found a prevalence of 57\% for urinary incontinence. In the present study, only 15\% of the sample reported urinary incontinence.
Thus, it seems that urinary incontinence is not a determinant for falls among independent, active, community-dwelling elderly women, given that the prevalence of falls in the present study and in the abovementioned study was $28 \%$ and $36 \%$, respectively. ${ }^{32}$

Functional mobility/the risk of falls was assessed using the TUG test, with no significant differences found between the groups. Another study assessed elderly women between the ages of 74 and 89 years and found no significant differences between female fallers and non-fallers based on their performance in the TUG test. ${ }^{33}$ The authors indicated that the absence of a difference in the age group of 74-89 years could be due to the low number of participants with mobility deficits, similar to the outcomes of the present study. ${ }^{33}$ Therefore, it is suggested that the TUG test should not be used to screen for the risk of falls among moderately-active, community-dwelling, elderly women, given that the results of this test were very similar in both groups (7.64 s for non-fallers and $7.94 \mathrm{~s}$ for fallers).

Concerning the fear of falls, which is considered one of the psychological factors related to the risk of falls, the participants had a mean score of 25 , which is associated with a history of sporadic falls. ${ }^{1}$ This result is significant since the non-fallers obtained the same score as the fallers. Indeed, a recent study by Kumar et al. ${ }^{34}$ suggested that one in every five people (relatively active communitydwellers) is afraid of falling. This syndrome has been associated with the following: low education levels; high BMI scores; a lower family income; difficulty in using public transport; the use of walking aids (canes, crutches); a low perception of physical health; self-reported balance issues and the inability to get up from a knee-height chair.

Reelick et al. ${ }^{4}$ assessed fear of falls, GS, step length and step variability among male and female elderly community-dwellers and found that those diagnosed with a fear of falls performed similarly in all of the abovementioned variables in comparison to those who did not fear falling. The results of the present study partly agree with an earlier study, ${ }^{4}$ in which the correlation between the TUG test and a fear of falls was assessed, with no significant 
associations recorded.

In the present study, there was a moderate, negative and significant correlation between the FES-I-Brazil and the gait cadence of elderly fallers, indicating that a greater fear of falls leads to a worsening in gait cadence. A recent study also confirmed a moderate, negative and significant association between the fear of falls, which was assessed using the FES-I-Brazil, and a gait speed of $4.6 \mathrm{~m} \cdot{ }^{30}$ These authors indicated that a slow GS, with a shorter step length, a greater support base and a longer double support time, could be associated with a pre-existing fear of falls. Other authors have also reported that a fear of falls can result in the simultaneous recruitment of agonist and antagonist muscles, leading to a rigid posture, an abnormal gait, inadequate postural strategies, uncertainty, dependence on stability devices (orthoses) and an increase in the risk of falls. ${ }^{5}$

A moderate, significant correlation was found between HGS and GS for both fallers and nonfallers, indicating that a stronger HGS leads to a faster GS. This result corroborates the findings of Stevens et al., ${ }^{35}$ who assessed 349 men and 280 women aged between 63 and 73 years and identified associations between a stronger HGS and a better performance in the three-meter walking test. These authors indicated that HGS is a good indicator of physical performance in this age group and could be more viable than completing a battery of physical performance tests in certain clinical situations. ${ }^{35}$ However, in the present study, no differences were found between fallers and nonfallers, which suggests that, despite the significant correlation between HGS and GS, the test was not sensitive enough to identify fallers.

The results of gait analysis on the treadmill confirmed no statistically significant differences between the groups. A prospective study by Moreira et al. ${ }^{30}$ sought to determine if the spatiotemporal parameters of gait could predict recurring falls in 148 women aged between 65 and 85 years. The results showed that neither GS nor the other gait parameters analyzed (cadence, step length, balance time and support time) significantly predicted recurrent falls. The same authors suggested that future studies should investigate the capacity of gait parameters to predict recurrent falls among healthy elderly individuals with no mobility deficiencies in "real life" situations, such as walking over obstacles or executing cognitive and motor tasks (talking, making calculations or carrying objects). It is possible that more challenging tasks may place more pressure on the physiological and cognitive systems and provide more data related to recurring falls and the risk of falls. Therefore, future studies should include gait assessments with challenges for moderately-active, elderly community-dwellers in order to investigate the gait differences between fallers and non-fallers.

A possible limitation of the gait analysis performed in the present study was that the task involving walking on a motorized treadmill. According to Kang \& Dingwell, ${ }^{28}$ treadmill assessments can artificially reduce the natural variability of the gait of an individual, when compared with normal walking, due to the fact that speed is vigorously maintained, without the possibility of adjustments. In the present study, eight of the participants were unable to walk at the speed required to assess gait on the treadmill and asked for the test to be stopped, claiming that "the speed was too high". In addition, 13 participants were unable to be present on the day of the assessment. Consequently, the number of elderly women assessed on the treadmill was lower than the 85 individuals included in this research.

The outcomes indicate that these methods do not provide specificity for assessments of intrinsic factors related to falls among moderately-active, community-dwelling elderly individuals, in relation to the differences between fallers and non-fallers. More precise methods are needed for this type of investigation. Furthermore, the present study did not assess a number of intrinsic factors, such as range of motion, balance and muscle reaction time. Therefore, these factors should be investigated in more detail in order to better characterize active, community-dwelling elderly fallers and non-fallers. Conversely, significant differences were found between the residences of elderly fallers and nonfallers. Thus, extrinsic factors seem to play an important role in falls and should be considered in future studies. 
Other limitations should be considered, including the cross-sectional design of the present study, which prevented the establishment of a causal relationship. In addition, the number of falls was under-estimated, due to the difficulty the participants faced when trying to remember falls in the previous 12 months. We also did not investigate the circumstances of the falls, such as: where the fall occurred (indoors or outdoors); what caused the fall; and if the individuals were able to support themselves and prevent a direct fall on the ground. Future studies should investigate these factors.

\section{CONCLUSION}

Appendicular muscle mass was below the cutoff points. However, muscle function and physical performance were normal, which meant that the elderly participants were not sarcopenic. Greater muscle strength indicated a higher gait speed.
Elderly fallers exhibited worse gait cadence and a greater fear of falls than non-fallers. Residential factors related to the risk of falls and safety resources were determined for falls, indicating the relevance of assessing the risk of falls in moderately active, community-dwelling elderly women.

\section{ACKNOWLEDGEMENTS}

The authors would like to thank: Prof. Oslei de Mattos from the Universidade Tecnológica Federal do Paraná; CNPq, for the grant provided to Prof. Anna Raquel Silveira Gomes (process no. 308696/2012-3); the Hospital de Clínicas of the Universidade Federal do Paraná, particularly the Functional Rehabilitation and Prevention Service and the Metabolic Unit; the Universidade Aberta da Maturidade (the Open University of the Third Age) of the Universidade Federal do Paraná and the Instituto Federal do Paraná (the Federal Institute of Paraná) for the financial assistance provided to Prof. Elisângela Valevein Rodrigues.

\section{REFERENCES}

1. Camargos FF, Dias RC, Dias JF, Freire MT. Cross-cultural adaptation and evaluation of the psychometric properties of the Falls Efficacy ScaleInternational Among Elderly Brazilians (FES-IBRAZIL). Rev Bras Fisioter 2010;14(3):237-43.

2. Clemson L, Mackenzie L, Ballinger C, Close JC, Cumming RG. Environmental interventions to prevent falls in community-dwelling older people: A meta-analysis of randomized trials. J Aging Health 2008;20(8):954-71.

3. Callisaya ML, Blizzard L, Schmidt MD, McGinley JL, Lord SR, Srikanth VK. A population-based study of sensorimotor factors affecting gait in older people. Age Ageing 2009;38(3):290-5.

4. Reelick MF, Van Iersel MB, Kessels RP, Rikkert MG. The influence of fear of falling on gait and balance in older people. Age Ageing 2009;38(4):435-40.

5. Delbaere K, Sturnieks DL, Crombez G, Lord SR. Concern about falls elicits changes in gait parameters in conditions of postural threat in older people. J Gerontol Ser A Biol Sci Med Sci 2009;64(2):237-42.
6. Melzer I, Benjuya B, Kaplanski J. Postural stability in the elderly: a comparison between fallers and nonfallers. Age Ageing 2004;33(6):602-7.

7. Iinattiniemi S, Jokelainen J, Luukinen H. Falls risk among a very old home-dwelling population. Scand J Prim Health Care 2009;27(1):25-30.

8. Krause KE, Mcintosh EI, Vallis LA. Sarcopenia and predictors of the fat free mass index in communitydwelling and assisted-living older men and women. Gait Posture 2012;35(2):180-5.

9. Shaw KA, Srikanth VK, Fryer JL, Blizzard L, Dwyer T, Venn AJ. Dual energy X-ray absorptiometry body composition and aging in a population-based older cohort. Int J Obes 2007;31(2):279-84.

10. Bijlsma AY, Pasma JH, Lambers D, Stijntjes M, Blauw GJ, Meskers CGM, et al. Muscle strength rather than muscle mass is associated with standing balance in elderly outpatients. JAMDA 2013;4(7):493-98.

11. Coin A, Sarti S, Ruggiero E, Giannini S, Pedrazzoni M, Minisola S, et al. Prevalence of sarcopenia based on different diagnostic criteria using DEXA and appendicular skeletal muscle mass reference values in an italian population aged 20 to 80. J Am Med Dir Assoc 2013;14(7):507-12. 
12. Barbosa-Silva TG, Bielemann RM, Gonzalez MC, Menezes AMB. Prevalence of sarcopenia among community-dwelling elderly of a medium-sized South American city: results of the COMO VAI? Study. J Cachexia Sarcopenia Muscle 2015;6(4):1-8.

13. Lebrão ML, Duarte YAO. Saúde, Bem-estar e Envelhecimento: o Projeto Sabe no município de São Paulo: uma abordagem inicial. Brasília, DF: Organização Pan- Americana da Saúde; 2003.

14. Cruz-jentoft AJ, Baeyens JP, Bauer JM, Boirie Y, Cederholm T, Landi F, et al. Sarcopenia: European consensus on definition and diagnosis. Age Ageing 2010;39(4):412-23.

15. Studenski S, Perera S, Patel K, Rosano C, Faulkner $\mathrm{K}$, Inzitari M, et al. Gait speed and survival in older adults. JAMA 2011;305(1):50-8.

16. Coelho FM, Narciso FM, Oliveira DM, Pereira DS, Teixeira AL, Teixeira MM, et al. sTNFR-1 is an early inflammatory marker in community versus institutionalized elderly women. Inflamm Res 2010;59(2):129-34.

17. Bertolucci PHF, Brucki SMD, Campacci SR. O mini-exame do estado mental em uma população geral: impacto da escolaridade. Arq Neuropsiquiatr 1994;52:1-7.

18. Sousa RL, Medeiros JGM, Moura ACL, Souza CLM, Moreira IF. Validade e fidedignidade da Escala de Depressão Geriátrica na identificação de idosos deprimidos em um hospital geral. J Bras Psiquiatr 2007;56(2):102-7.

19. Marx FC, Oliveira ML, Bellini CG, Ribeiro MCC. Tradução e validação cultural do questionário algofuncional de Lequesne para osteoartrite de joelhos e quadris para a língua portuguesa. Rev Bras Reumatol 2006;46(4):253-60.

20. Imoto AM, Peccin MS, Rodrigues R, Mizusaki JM. Tradução e validação do questionário FAOS - Foot and ankle outcome score para língua portuguesa. Acta Ortop Bras 2009;17(4):232-5.

21. Souza AC, Magalhães LC, Teixeira-Salmela LF. Adaptação transcultural e Análise das propriedades psicométricas da versão brasileira do Perfil de Atividade Humana. Cad Saude Publica 2006;22(12):2623-36.

22. Lino VTS, Pereira SEM, Camacho LAB, Ribeiro Filho ST, Buksman S. Adaptação transcultural da Escala de Independência em Atividades da Vida Diária (Escala de Katz). Cad Saúde Pública 2008;24(1):103-12.
23. Lawton MP, Brody EM. Assessment of older people: self-maintaining and instrumental activities of daily living. Gerontologist 1970;19(3):179-86.

24. Menz HB, Morris ME, Lord SR. Foot and ankle risk factors for falls in older people: a prospective study. J Gerontol Ser A Biol Sci Med Sci 2006;61(8):866-70.

25. Bohannon RW. Measurement of Sit-to-Stand among older adults. Top Geriatric Rehabil 2012;28(1):11-6.

26. Bohannon RW. Reference values for the timed up and go test: a descriptive meta-analysis. J Geriatr Phys Ther 2006;29(2):64-8.

27. Zhang YB, Wang WQ. Reliability of the Fukuda Stepping Test to determine the side of vestibular disfunction. J Int Med Res 2011;39(4):1432-37.

28. Kang HG, Dingwell JB. Effects of walking speed, strength and range of motion on gait stability in healthy older adults. J Biomech 2008;41(14):2899-905.

29. Hallal CF, Marques NR, Castro A, Spinoso DH, Rossi DM, Navega MT, et al. Variabilidade de parâmetros eletromiográficos e cinemáticos em diferentes condições de marcha em idosos. Motriz 2013;19(1);141-50.

30. Moreira BS, Sampaio RF, Kirkwood RN. Spatiotemporal gait parameters and recurrent falls in community-dwelling elderly women: a prospective study. Braz J Phys Ther 2015;19(1):61-9.

31. Cruz DT, Ribeiro LC, Vieira MT, Teixeira MTB, Bastos RR, Leite ICG. Prevalência de quedas e fatores associados em idosos. Rev Saúde Pública 2012;46(1):138-46.

32. Borges PLC, Bretas RP, Azevedo SF, Barbosa JMM. Perfil dos idosos frequentadores de grupos de convivência em Belo Horizonte, Minas Gerais, Brasil. Cad Saúde Pública 2008;24(12):2798-808.

33. Thrane G, Joakimsen RM, Thornquist E. The association between timed up and go test and history of falls: The Tromsø study. BMC Geriatr 2007;12:1-7.

34. Kumar A, Carpenter H, Morris R, Iliffe S, Kendrick D. Which factors are associated with fear of falling in community-dwelling older people? Age Ageing 2014;43(1):76-84.

35. Stevens P, Syddall HE, Patel HP, Martin HJ, Cooper $\mathrm{C}$, Aihie Sayer A. Is grip strength a good marker of physical performance among community-dwelling older people? J Nutr Health Aging 2012;16(9):769-74. 